\title{
PENGGUNAAN PERALATAN PENGUPAS KULIT MANIS KOPI DI DESA BUAH RAYA KABUPATEN KARO
}

\author{
Junedi Ginting ${ }^{1}$, Juliati Br Tarigan ${ }^{2}$ \\ ${ }^{1,2}$ Fakultas Matematika Dan Ilmu Pengetahuan Alam Universitas Sumatera Utara \\ Email: edittings@yahoo.com
}

\begin{abstract}
ABSTRAK
Kegiatan pengabdian ini telah dilaksanakan dan berjalan dengan baik sesuai dengan tujuan untuk membantu masyarakat petani kopi di Desa Buah Raya untuk mengupas kulit manis kopi dari biji dan memisahkan kulit manis tersebut dari bijinya. Alat yang digunakan yaitu 1 set peralatan yang dilengkapi dengan mesin dengan bahan bakar minyak premium dengan output 1 biji kopi ditampung dalam fiber/ember sedangkan output 2 kulit manis kopi yang ditampung dalam karung goni. Pengujian hasil produksi alat dilakukan dengan memasukkan biji kopi dengan kulit manis ke input alat dan outputnya diperhatikan sesuai dengan yang diharapkan dengan menyetel katup kuantitas input, katup tekanan udara dan tinggi rendahnya gas mesin. Jika penyetelan sudah berada pada posisi yang benar dan masih terdapat output yang masih ada kulit manis maka dapat dikupas ulang dengan memasukkannya kembali ke input alat. Hasil pengupasan kulit manis dari biji kopi oleh alat diperoleh rata-rata sebesar $92,29 \%$ dan $7,1 \%$ merupakan kulit manis.
\end{abstract}

\begin{abstract}
This devotional activity has been implemented and runs well according to purpose to help the coffee farming community in the village of Buah Raya to peel the cinnamon coffee from the seeds and separate the sweet skin from the seeds. The tool used is 1 set of equipment equipped with engine with premium fuel oil with output of 1 coffee beans accommodated in fiber / bucket while the output 2 cinnamon coffee which is accommodated in the sack. Testing of equipment production is done by inserting the coffee bean with sweet skin to the input of the equipment and its output is considered as expected by adjusting the input quantity valve, air pressure valve and high low engine gas. If the adjustment is in the correct position and there is still a sweet leather output it can be peeled back by putting it back into the tool input. Results of stripping of cinnamon from coffee beans by means obtained an average of $92.29 \%$ and $7.1 \%$ is sweet skin.
\end{abstract}

\section{PENDAHULUAN}

Desa Buah Raya berbatasan dengan Lau Biang sebelah Barat, Desa Bintang Meriah sebelah Timur, Desa Lau Buluh sebelah Utara, Desa Limang dan Desa Perbesi sebelah Selatan. Desa Buah Raya berada di Kecamatan Kuta Buluh Kabupaten Karo dengan jarak $\pm 113 \mathrm{~km}$ dari Kota Medan.

Secara umum masyarakat Desa Buah Raya memiliki variasi cocok tanam, termasuk tanaman kopi. Pengolahan buah kopi oleh warga untuk memisahkan biji kopi dengan kulit manisnya belum ada yang dilakukan oleh warga masyarakat petani kopi karena rendahnya wawasan masyarakat terkait peralatan tersebut sehingga warga menjual hasil panen kopinya dengan kulit manis dengan harga yang relatif murah dibanding dengan tanpa adanya kulit manis. Dengan menggunakan alat pengupas kulit manis kopi dari bijinya yang merupakan pemberian tim pengabdian USU terhadap kelompok tani kopi di desa Buah Raya maka seluruh warga masyarakat kelompok petani kopi sudah dapat menggunakan alat untuk mengupas kulit manis dari biji kopi sehingga harga jualnya di pasar semakin membaik yang berdampak positif untuk meningkatkan pendapatan masyarakat kelompok petani kopi. Kehadiran peralatan ini mendorong motivasi warga untuk memperluas lahan cocok tanam kopi dan merangsang 
Junedi Ginting. et al. Pengunaan Peralatan Pengupas Kulit Manis Kopi Di Desa Buah Raya Kabupaten Karo

masyarakat untuk bercocok tanam kopi bagi warga yang belum bercocok tanam kopi.

Dengan demikian asosiasi kopi karo yang telah terbentuk lebih mudah untuk mendobrak pasar lokal maupun internasional serta melakukan tindakan kajian ke arah yang lebih baik dengan menghadirkan ahli/pakar internasional karena kuantitas yang cukup memadai, menghadirkan perguruan tinggi/ilmuwan untuk meneliti lebih jauh dan memanfaatkan limbah kopi sebagai obat, pupuk dan pakan ternak.

\section{ALAT DAN BAHAN}

1 set alat dilengkapi mesin, BBM premium, goni, fiber/ember dan biji kopi.

\section{METODE PELAKSANAAN}

1. Di setel katup input agar biji kopi yang akan dikupas kulit manisnya sesuai dengan kekuatan mesin untuk mendapatkan hasil pengupasan kulit manis yang baik.

2. Di setel katup tekanan udara untuk memisahkan kulit manis dengan bij kopi yang telah dikupas alat.

3. Di pasang goni pada output alat untuk menampung kulit manis kopi.
4. Di letakkan fiber/ember pada output alat untuk menampung biji kopi.

5. Mesin dihidupkan, jika susah maka on kan chooke mesin setelah mesin hidup segera off kan chooke mesin.

6. Di setel tinggi/rendahnya gas mesin untuk mendapatkan kesesuaian secara menyeluruh.

7. Masukkan biji kopi ke input alat dan jika masih kurang memuaskan hasilnya dapat dimasukkan kembali ke input alat untuk pengupasan ulang.

8. Jika pengupasan kulit manis kopi sudah habis di input tunggu \pm 3 menit kemudian mesin dimatikan untuk memastikan biji kopi sudah habis di pipa saluran alat agar untuk menghidupkan mesin kembali tetap ringan.

\section{HASIL DAN ANALISA}

Peralatan bekerja dengan baik karena mampu mengupas kulit manis kopi dan memisahkannya dari bijinya. Jika hasil pengupasan masih terdapat kulit manis maka dapat dimasukkan kembali ke input untuk melakukan pengupasan kembali oleh alat.

Kualitas hasil produksi peralatan untuk tingkat kekeringan kopi yang sama maka sampel dikelompokkan menjadi 5 bagian masing-masing beratnya $2 \mathrm{~kg}$ dengan hasil sebagai berikut:

Tabel Rincian hasil keluaran peralatan pengupas kulit manis kopi

\begin{tabular}{|c|c|c|c|c|}
\hline No. & Sampel & Biji Utuh (gr) & Biji Pecah (gr) & $\begin{array}{c}\text { Ampas/Kulit Manis } \\
\text { Kopi (gr) }\end{array}$ \\
\hline 1. & $1(2 \mathrm{~kg})$ & 1835 & 120 & 42 \\
\hline 2. & $2(2 \mathrm{~kg})$ & 1860 & 100 & 36 \\
\hline 3. & $3(2 \mathrm{~kg})$ & 1841 & 115 & 40 \\
\hline 4. & $4(2 \mathrm{~kg})$ & 1854 & 105 & 38 \\
\hline 5. & $5(2 \mathrm{~kg})$ & 1840 & 116 & 40 \\
\hline
\end{tabular}

Persentasi biji utuh yang diperoleh:

Sampel 1: 1835/2000 x 100\% = 91,75\%

Sampel 2: $1860 / 2000 \times 100 \%=93 \%$

Sampel 3: $1841 / 2000 \times 100 \%=92 \%$

Sampel 4: $1854 / 2000 \times 100 \%=92,7 \%$

Sampel 5: $1840 / 2000 \times 100 \%=92 \%$

Rata-rata biji utuh yang diperoleh: $92,29 \%$ 
Berdasarkan nilai harga kopi di pasar tanpa kulit manis jauh lebih beruntung dengan menjual kopi tanpa kulit manis karena harganya $35 \%$ diatas harga kopi dengan kulit manis.

Dengan keberadaan peralatan tersebut maka masyarakat kelompok petani kopi di desa Buah Raya dan desa tetangga yang masyarakatnya bercocok tanam kopi yang berbatasan ladangnya dengan ladang desa Buah Raya seluruhnya telah menggunakan peralatan hasil pemberian tim pengabdian USU agar kopi mereka dijual ke pasar dalam bentuk biji tanpa kulit manis (kulit ari) karena selisih harga rata-rata naik mencapai Rp. 6000/kg tanpa kulit manis dengan adanya kulit manis. Rata-rata berat kulit manis per kilogram biji kopi sebesar 11 gram. Jadi masyarakat jauh sangat beruntung menjual hasil panen kopinya tanpa kulit manis.

Dengan keberadaan alat di desa Buah Raya hasil pemberian tim pengabdian USU memberikan penambahan wawasan pengolahan hasil tani kopi tehadap masyarakat petani kopi di desa Buah Raya juga terhadap desa lainnya yang mana pada saat ada pesta di desa Buah Raya maka masyarakat saling tukar wawasan/informasi yang menyebabkan masyarakat petani kopi desa Lau Buluh menanyakan tentang peralatan terhadap tim pengabdian USU. Hasilnya masyarakat petani kopi di desa Lau Buluh Kecamatan Kuta Buluh telah memiliki alat pengupas kulit manis kopi secara manual karena harga lebih murah yang langsung dibeli oleh masyarakat kelompok petani kopi di desa tersebut. Masyarakat desa Lau Buluh mendapat informasi tentang alat ini dari tim pengabdian USU.

Jadi hasil kegiatan tim pengabdian USU bukan hanya berdampak positif terhadap masyarakat kelompok petani kopi di desa Buah Raya namun menjadi triger terhadap kelompok tani kopi di desa lain di Kecamatan tersebut sehingga dengan kegiatan ini tim pengabdian USU berhasil meningkatan pendapatan keuangan masyarakat untuk mencapai kesejahteraannya dengan memanfaatkan hasil perkembangan teknologi.

Hasil produksi alat menunjukkan bahwa terdapat biji kopi yang pecah hal ini disebabkan biji kopi yang akan dikupas oleh alat masih kurang kering sehingga pada saat terjadi gesekan antara poros dengan plat ban pada proses pelepasan kulit manis kopi dari bijinya biji kopi menjadi pecah. Untuk mengatasi hal tersebut keringkanlah biji kopi dibawah sinar matahari agar hasil pengupasan kulit manis kopi menghasilkan biji kopi yang utuh sempurna tanpa adanya yang pecah.

\section{KESIMPULAN}

1. Biji kopi yang akan dilepas kulit manisnya harus benar-benar kering untuk menghindari terjadinya biji kopi yang pecah pada saat pengupasan kulit manis oleh peralatan.

2. Peralatan yang telah dioperasikan bekerja dengan baik namun jika masih ada terdapat kulit manis kopi hasil pengupasan alat maka dapat dilakukan pengupasan kembali.

\section{SARAN}

1. Tingkat kematangan kopi saat panen agar sangat diperhatikan karena mempengaruhi hasil pengupasan kulit manis kopi.

2. Biji kopi yang akan dilepas kulit manisnya sebaiknya dipastikan benarbenar kering untuk menghindari terjadinya biji kopi yang pecah.

3. Buah kopi yang dipanen sebaiknya direndam ke air dan yang tenggelam merupakan kopi yang berkualitas baik sedangkan yang terapung kopi yang berkualitas kurang baik.

4. Sebelum melakukan pengupasan kulit manis kopi maka pastikan fiber/ember telah diletakkan di output biji kopi dan sarung goni telah terpasang di output penampungan kulit manis kopi.

\section{UCAPAN TERIMA KASIH}

Terima kasih kepada Lembaga Pengabdian pada Masyarakat Universitas Sumatera Utara yang telah membiayai pengabdian ini melalui Dana NON PNBP USU Tahun anggaran 2017 sesuai dengan Kontrak Perjanjian Penugasan Pelaksanaan Pengabdian kepada Masyarakat Program Mono Tahun, Tahun Anggaran 2017 Nomor: 3221/UN5.2.3.2.1/PPM/2017, Tanggal 24 Juli 2017. 
Junedi Ginting. et al. Pengunaan Peralatan Pengupas Kulit Manis Kopi Di Desa Buah Raya Kabupaten Karo

\section{DAFTAR PUSTAKA}

Astu Pudjanarsa, Ir. MT dan Djati Nursuhud, Prof.Ir. MSME, 2009. Mesin Konversi Energi, Penerbit: Andi Publisher.

Bambang Prastowo, dkk. 2010. Budidaya dan Pasca Panen Kopi, Pusat Penelitian dan Pengembangan Perkebunan Jakarta.
Rahmad Nurudin dan Arya Mahendra Sakti, 2014. Rancang Bangun Mesin Pengupas Kulit Kopi. JRM. Volume 01 Nomor 02 Tahun 2014. 11-15.

Syahrir Arief, 2013: PERANCANGAN MESIN PENGUPAS KULIT KOPI. Proceeding Seminar Nasional Tahunan Teknik Mesin XII (SNTTM XII) \&

Thermofluid IV 23-24 Oktober 2013. 